J ournal of Fish Biology (1995) 47, 248-255

\title{
Intraseasonal characterization of glass eel migration in the $R$ iver Tiber: space and time dynamics
}

\author{
E. Ciccotti*, T. R icci*, M . Scardi ${ }^{*}$, E. F Resi* and S. Cataudella* \\ *Dipartimento di Biologia, Laboratorio di E cologia Sperimentale ed Acquacoltura, \\ U niversità 'T or V ergata ', via della Ricerca Scientifica, 00133 R ome, and \\ †Stazione Z oologica 'A nton D ohrn' di Napoli, Villa Comunale, 80121 Naples, Italy
}

(Received 21 J uly 1993, Accepted 23 September 1994)

\begin{abstract}
G lass eel (A nguilla anguilla) upstream migration was studied in the River Tiber estuary to obtain a better understanding of spatial and temporal migration dynamics within the season of ascent. U sing data from glass eel fisheries, time series analysis of daily catches per unit of effort revealed a fortnightly cycle that can be related to invasion waves possibly corresponding to tidal currents. The amplitude of these waves appeared to correspond to the tidal area of the estuary. F urthermore, glass eels apparently had a delay in this area before resuming upstream migration. (c) 1995 The F isheries Society of the British Isles
\end{abstract}

K ey words: glass eel; A nguilla anguilla; upstream migration; R iver Tiber.

\section{INTRODUCTION}

E uropean glass eel (Anguilla anguilla L.) migration has been monitored widely because they are harvested commercially in many estuaries of Europe, on both the A tlantic and the M editerranean coasts. A survey of the literature points to a dramatic decline in catches for several European countries in the last decade (M oriarty, 1990, 1993). H owever, capture data for I taly are scarce, despite the long standing glass eel fisheries both in the Tyrrhenian and North-Adriatic regions.

In the lower stretch of the $\mathrm{R}$ iver $\mathrm{T}$ iber, a large eel population is present which is prevented from moving further upstream by a series of dams, the first of which is located about $40 \mathrm{~km}$ from the sea. This is the main cause of a high yellow eel density exploited by a fishery also as a consequence of the increased seed demand from intensive eel culture.

The aim of this study was to gain further information about glass eel recruitment to the River Tiber, and to understand the dynamics of glass eel migration through the estuary.

\section{MATERIALS AND METHODS}

The study area was located at the mouth of the River Tiber (L atium, Central Italy), whose coastal plain estuary (Pritchard, 1952) consists of an enlargement of the river axis into which sea water intrudes, creating a salinity stratification. This salinity front extends about $7 \mathrm{~km}$ from the river mouth, although its amplitude depends on tide and river discharge. The study area stretched from the sea to approximately $10 \mathrm{~km}$ upstream. A long this stretch, 20 fixed stations $600 \mathrm{~m}$ apart were chosen where elver fyke nets were 


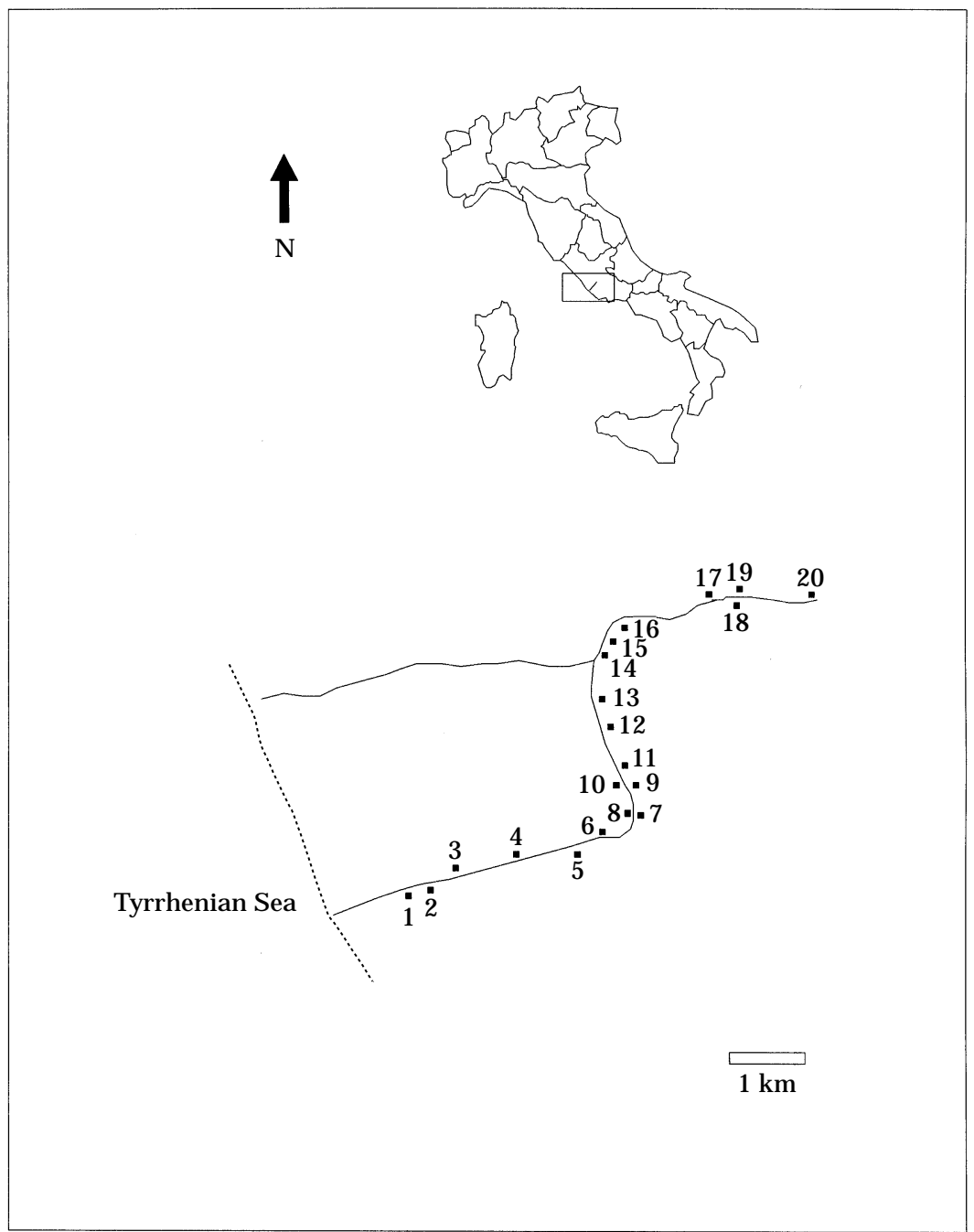

F IG. 1. F ishing stations where fyke nets were installed for the monitoring of glass eel upstream migration in the Tiber estuary.

used ( $F$ ig. 1). F requency of fishing was daily, except during unusual events such as river floods and storms.

G lobal data from two fishing seasons were available (Table I), from D ecember 1990 to M arch 1991 and from N ovember 1991 to M arch 1992, but daily data were available only from J anuary 1991. The fyke nets (total length $4.6 \mathrm{~m}$, two capture chambers, mouth $1.2 \mathrm{~m}$ wide, mesh $2 \mathrm{~mm}$ ) were provided with two large wings ( $2.5 \mathrm{~m}$ long, mesh $2 \mathrm{~mm}$ ) to direct swimming glass eels towards the mouth. Fyke nets were installed (one per station) usually at noon, tied to wooden supports with the mouth oriented downstream, and withdrawn the following morning. Catches for each fyke net and total catch of the day were weighed. The number of nets installed and the frequency of emptying varied with the intensity of glass eel ascent. A nalyses were therefore carried out using daily catches per unit of effort (cpue) as the most representative relative abundance index. C pue was calculated as daily total catch per number of fyke nets installed each day.

A $n$ autocorrelation was performed on the cpue time series using M oran's index I to detect a temporal periodicity in catches within the season of migration. This auto- 
TABLE I. Comparative aspects of fisheries in the two seasons

\begin{tabular}{lcc}
\hline & $\begin{array}{c}\text { First season } \\
1990-1991\end{array}$ & $\begin{array}{c}\text { Second season } \\
1991-1992\end{array}$ \\
\hline Duration (days) & & 153 \\
F ishing & 117 & 73 \\
N o fishing & $94 *$ & 80 \\
Total catch (kg) & 23 & 256 \\
M ean daily catch (kg) & 446 & $3 \cdot 5$ \\
M ean sets of gear installed per day & $4 \cdot 7$ & 6 \\
M ean duration of fishing effort per day (h) & 7 & 15 \\
\hline
\end{tabular}

*D aily catches for the first season were available only from J anuary (i.e. 42 days).

correlation index (M oran, 1950), developed for the analysis of spatial series, was selected because the cpue time series was scattered. Two-tail tests were performed, with a chosen probability level of $P<0 \cdot 05$, on the whole cpue series of the two seasons and separately for the two seasons.

To study the spatial pattern of migration in the estuary, cross-correlations were performed on the catch time series from the second season. Stations 19, 15, 11, 7, 6 and 3 (see F ig. 1) were chosen, because these were the stations most frequently used during the two fishing seasons. The correlations were calculated for paired stations on catch time series shifted for time lags from 0 to 90 days.

\section{RESULTS}

The second fishing season was longer than the first (Table I), but the days of actual fishing were fewer, because for the most part of N ovember 1991 a flood hampered the installation of nets.

\section{TIME DYNAMICS}

$M$ aximum abundances were recorded during $F$ ebruary of both seasons (Fig. 2). In $\mathrm{M}$ arch the yield decreased progressively towards minimum values. Therefore, the fishing season ended in both years at the end of $M$ arch. A utocorrelation showed the existence of periodicity within the whole cpue time series ( $\mathrm{Fig}$. 3). The periods which explained the greater part of the variance of the series were those for which the correlation coefficients, $r$, were significantly different from zero, i.e. higher than the confidence limits $p(r)$. A strong positive autocorrelation was found for very short time lags ( 1 to 2 days), which accounted for the dependence of catches within short term cycles. In the analysis of periodic data series, this is usually due to the existence of a longer cycle. In fact the most striking result was a fortnightly cycle: within the first season, autocorrelation was positive and significant at 13 to 14 days. Even at a time lag of about 1 year, i.e. comparing the first and the second fishing season, there was strong evidence of a 14-day period. There was also weak evidence for a second peak of positive autocorrelation at about 28 days, but this was probably a side effect of the fortnightly cycle.

Significant negative autocorrelations were observed, within the second fishing season, at 7 and 21 days ( $F$ ig. 4) due to the same basic frequency of the data series. 

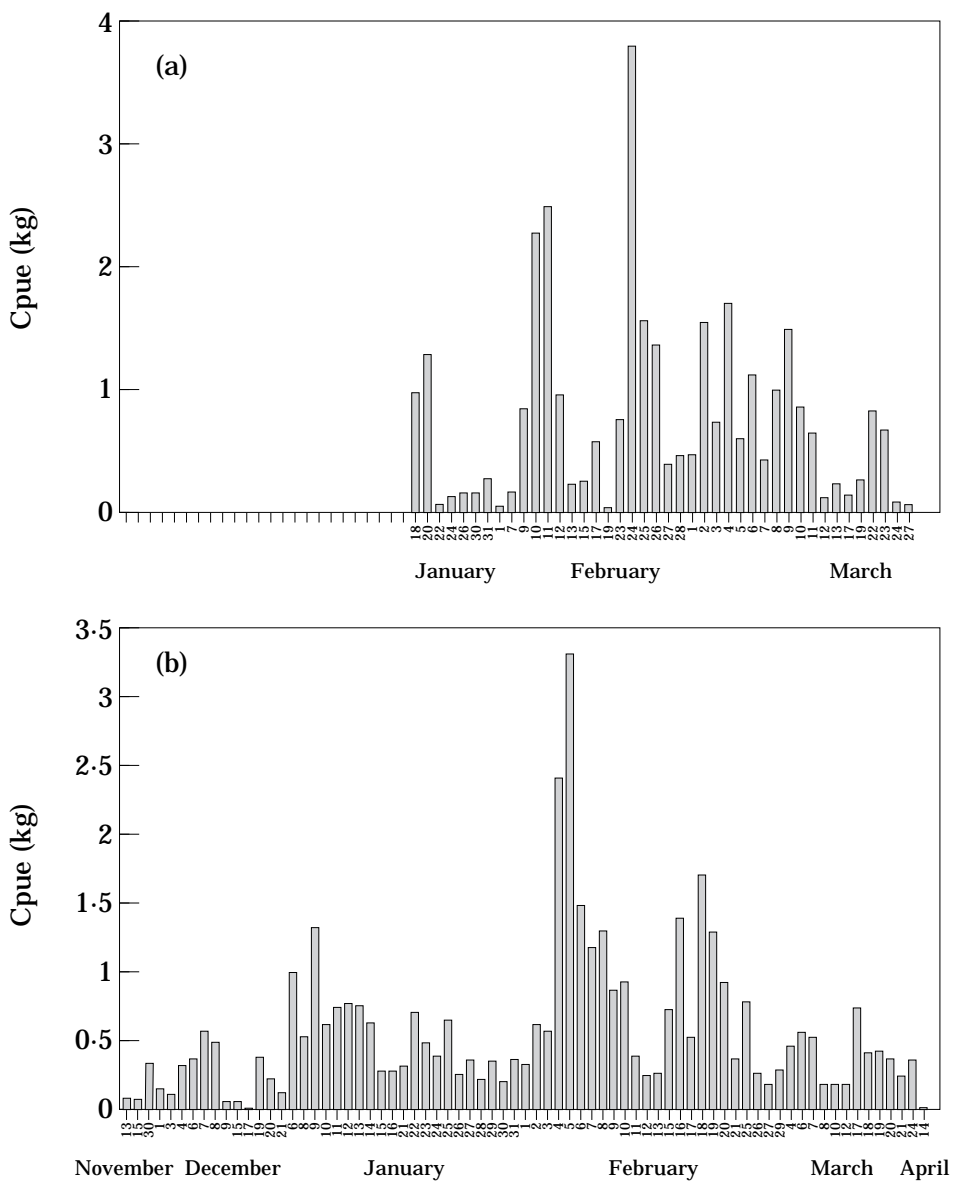

F IG. 2. Catches per unit of effort (daily total catch/number of fyke nets installed each day) during glass eel upstream migration in the Tiber estuary. (a) First fishing season (J anuary-M arch 1991). (b) Second fishing season (N ovember 1991-A pril 1992).

SPACE DYNAMICS

The significant positive correlation coefficients at definite time lags between pairs of stations point to a direct proportionality in catches between those stations (Table II). Significant positive instantaneous cross correlations recurred at intervals of 0 to 3 days, between all pairs of stations except those farthest away. Peaks of high positive cross correlations with a period of 14 days can be observed for many pairs of stations. This cyclic cross correlation was always significant $(P<0.01)$ for all stations compared with station 3 (downstream) (except for station 19 for which data were scarce) and for many pairs of neighbouring stations. Cross correlation between stations at longer time intervals occurred in many cases, with intervals ranging from 28 to 56 days.

\section{DISCUSSION}

A nnual recruitment in the $\mathrm{R}$ iver Tiber was determined mainly by the timing of ascent, which took place between N ovember and February. A s fishing effort 


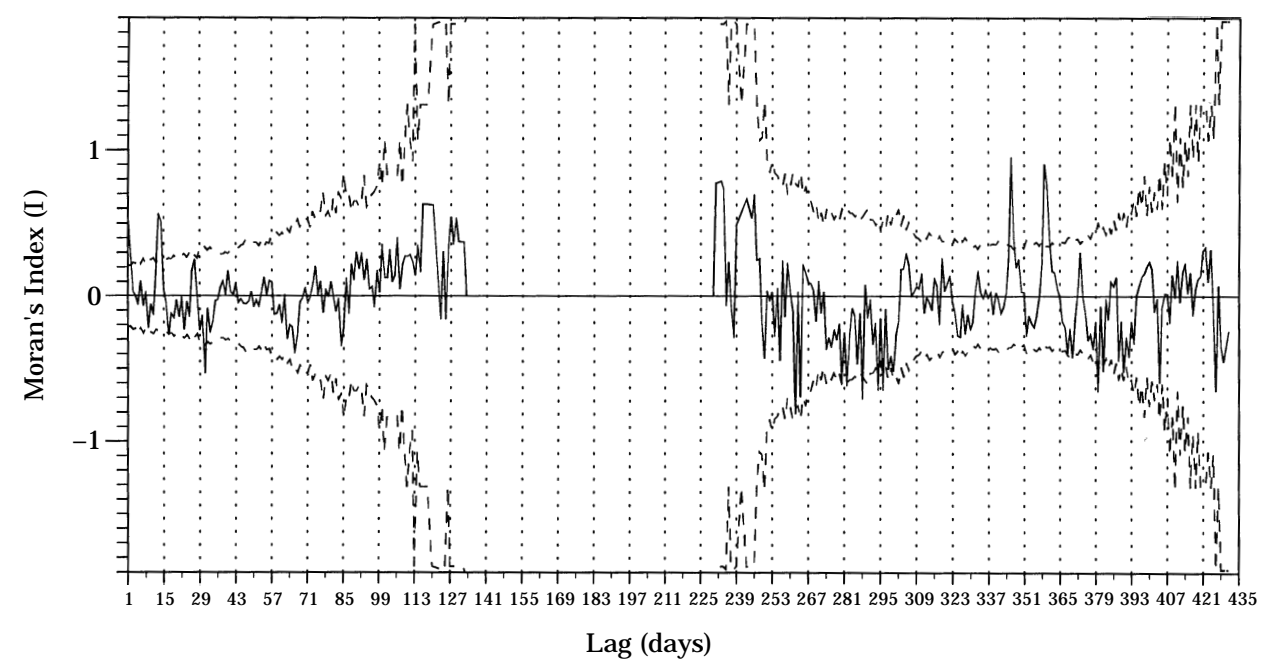

F IG. 3. A utocorrelation (M oran's) diagram of the two fishing seasons cpue time series of glass eels during upstream migration in the Tiber estuary (dashed lines are 95\% confidence levels).

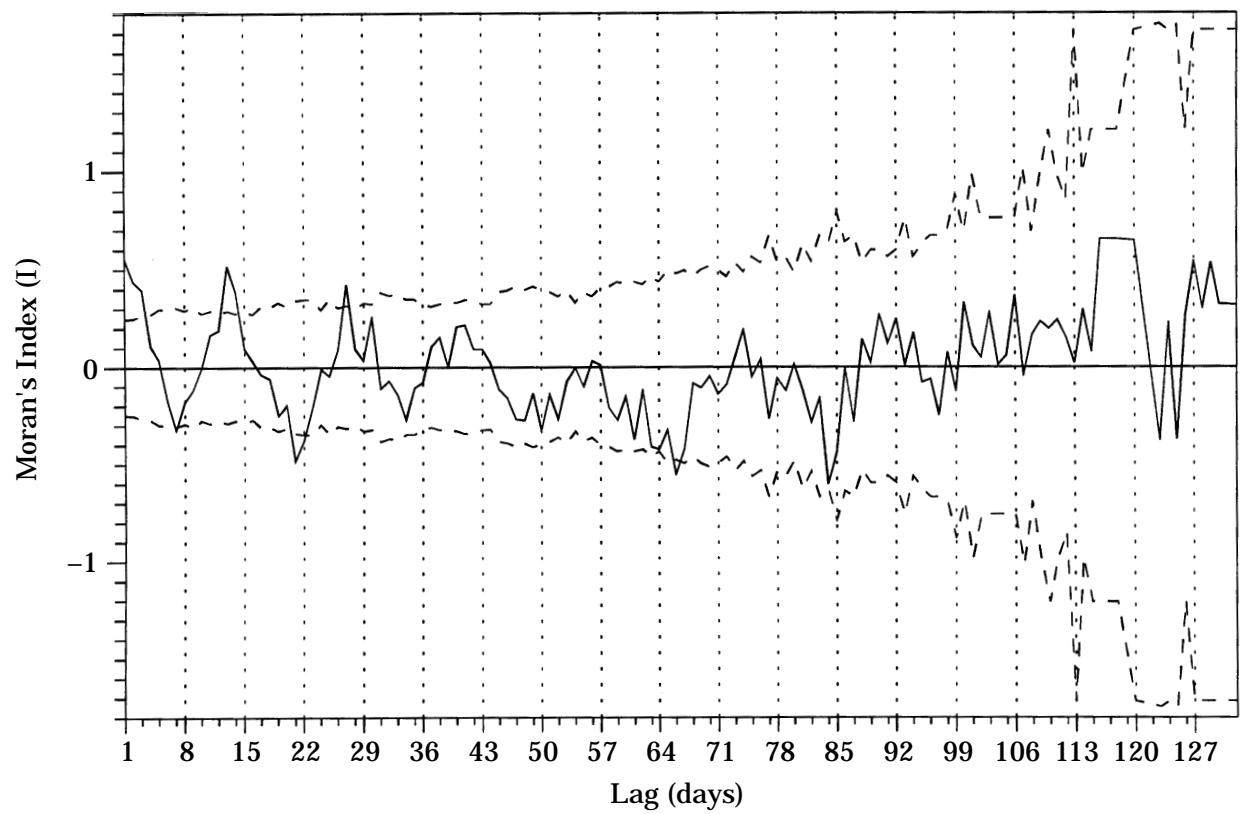

F IG. 4. A utocorrelation (M oran's) diagram of the second fishing season cpue time series of glass eels during upstream migration in the Tiber estuary (dashed lines are $95 \%$ confidence levels).

remained reasonably constant in the two sampled seasons, daily catches were comparable. The fortnightly cycle in the cpue time series points to a periodicity of glass eel ascent, and supports the hypothesis that glass eel migration consists of waves of invasion (Boëtius \& Boëtius, 1989). This oscillatory pattern, observed by many authors (J ellyman, 1979; Cantrelle, 1984; G andolfi et al., 1984; Sorensen \& Bianchini, 1986; Boëtius \& Boëtius, 1989), is probably related 
TABLE II. Time lags $d(t)$ in days at which $r$, correlation coefficient between catches in paired stations, is significant $(*=P<0.05$; $* *=\mathrm{P}<0.01)$

\begin{tabular}{|c|c|c|c|c|c|c|}
\hline \multirow{2}{*}{ Station } & \multicolumn{6}{|c|}{ Station } \\
\hline & 19 & 15 & 11 & 7 & 6 & 3 \\
\hline 19 & - & $\begin{array}{l}0^{* *} \\
36^{*} \\
45^{* *} \\
53^{*}\end{array}$ & $\begin{array}{c}0^{*} \\
40^{*} \\
42^{* *} \\
43^{* *}\end{array}$ & $\begin{array}{c}0^{*} \\
35^{*} \\
37^{* *} \\
38^{* *}\end{array}$ & $\begin{array}{l}27 * \\
37^{* *}\end{array}$ & - \\
\hline 15 & & - & $\begin{array}{c}0^{* *} \\
2^{* *} \\
5^{*} \\
14^{*}\end{array}$ & $\begin{array}{r}0 * * \\
40^{* *} \\
42^{* *}\end{array}$ & $\begin{array}{c}0^{* *} \\
1^{* *} \\
15^{*} \\
30^{* *} \\
42^{*} \\
56^{* *}\end{array}$ & $\begin{array}{c}0^{*} \\
3^{*} \\
12^{*} \\
13^{* *} \\
14^{*} \\
26^{* *} \\
39^{*} \\
40^{* *} \\
41^{*}\end{array}$ \\
\hline 11 & & & - & $\begin{array}{c}0^{* *} \\
1^{*} \\
2^{* *} \\
14^{*} \\
22^{*} \\
35^{* *} \\
38^{* *}\end{array}$ & $\begin{array}{c}1^{*} \\
51^{* *} \\
52^{*} \\
53^{*}\end{array}$ & $\begin{array}{r}0^{* *} \\
11^{* *} \\
26^{* *} \\
27^{* *} \\
48^{* *}\end{array}$ \\
\hline 7 & & & & - & $\begin{array}{c}0^{* *} \\
1^{*} \\
29^{*}\end{array}$ & $\begin{array}{c}0 * * \\
11^{*} \\
12^{*} \\
13^{* *} \\
26^{* *}\end{array}$ \\
\hline 6 & & & & & - & $\begin{array}{c}0 * * \\
1 * \\
11^{* *} \\
22^{*} \\
39^{* *} \\
40^{* *}\end{array}$ \\
\hline
\end{tabular}

to the selective tidal stream transport described both for Anguilla rostrata (L esueur) (M cCleave \& K leckner, 1982; Wippelhauser \& M cCleave, 1987; M cCleave \& W ippelhauser, 1987) and A . anguilla glass eels (Creutzberg, 1963; $\mathrm{G}$ ascuel, 1986). A ccording to this model, the rate of upstream transport depends upon the interactions between the behaviour of the fish and the hydrographic conditions in the estuary. The estuarine hydrodynamics should in fact bring about a natural trapping of animals in the tidal front, the location of which depends on the freshwater discharge and the tide strength.

The peaks of abundance in catches with a 2-week period can probably be ascribed to successive runs of glass eels in coincidence with tidal currents in the Tiber estuary. This seems to be confirmed by the proportionality in catches between all stations with a time interval of 0 to 3 days: in fact the greater the tidal 
amplitude, the farther upstream the glass eels should be transported ( $G$ ascuel, 1986). The amplitude of these waves of invasion declined towards the upstream part of the study area, probably due to a transition stage in this stretch of the river. A fter invasion of fresh water from the sea, glass eels remain in estuarine and tidal areas while they undergo an adaptation period in behaviour and morphology before their upstream migration (D eelder, 1958, 1960; Tesch, 1971; Weber, 1986). M cCleave \& W ippelhauser (1987) suggested that it is the tidal regime that determines the location of this ' transition area ', rather than salinity or temperature choices. Internal morphology of glass eels caught during migration also indicates that they remain in brackish waters (Ciccotti et al., 1993). The correlation between catches in paired stations at time intervals other than 0 to 3 days further supports a slowing and/or halt in migration, since it points to a delayed resumption of migratory movement. The cyclic correlations between catches at time lags of 14 days suggest, however, that further movements towards the upstream stretch of the study area were still linked to tidal currents. A ccording to Gascuel (1986), upstream of the tidal area the moving forward of glass eels involves an active swimming behaviour. It is during this second phase that glass eels, having now developed into elvers, are able to move further upstream and colonize the upper part of the river system.

This study was supported by a grant from the Italian M inistry of the M erchant $\mathrm{N}$ avy, law 41/82. The authors thank Alfredo and Cesare Bergamini, Giovanni, Franco and $\mathrm{N}$ ando $\mathrm{G}$ abiati, professional fishermen on the River Tiber.

\section{R eferences}

Boëtius, I. \& Boëtius, J. (1989). A scending elvers, A nguilla anguilla, from five European localities. A nalyses of pigmentation stages, condition, chemical composition and energy reserves. Dana $7,1-12$.

Cantrelle, I. (1984). Les populations de civelles d'A nguilla anguilla L. en migration dans I'estuaire de la Gironde. Vie et M ilieu 34, 109-116.

Ciccotti, E., M acchi, E., Rossi, A., Cataldi, E. \& Cataudella, S. (1993). Glass eel (A nguilla anguilla) acclimation to freshwater and seawater: morphological changes of the digestive tract. J ournal of A pplied I chthyology 9, 74-81.

Creutzberg, F. (1963). The role of tidal streams in the navigation of migrating elvers (A nguilla vulgaris Turt.). Ergebnisse der Biologie 26, 118-127.

D eelder, C. L. (1958). On the behaviour of elvers (A nguilla vulgaris Turt.) migrating from the sea into fresh water. J ournal du Conseil Permanent International pour l'Exploration de la M er 24, 135-146.

D eelder, C. L . (1960) E rgebnisse der holländischen U ntersuchungen über den G lasaalzug. A rchiv für Fischereiwissenschaft 11, 1-10.

G andolfi, G., Pesaro, M . \& Tongiorgi, P. (1984). Environmental factors affecting the ascent of elvers, Anguilla anguilla (L.), into the A rno river. Oebalia X (N.S.), 17-35.

G ascuel, D . (1986). F low-carried and active swimming migration of the glass eel (A nguilla anguilla) in the tidal area of a small estuary on the French A tlantic coast. $\mathrm{H}$ elgoländer M eeresuntersuchungen 40, 321-326.

J ellyman, D. J. (1979). U pstream migration of glass-eels (A nguilla spp.) in the Waikato river. $N$ ew $Z$ ealand J ournal of $M$ arine and Freshwater R esearch 13, 13-22.

M cCleave, J. D. \& K leckner, R. C. (1982). Selective tidal stream transport in the estuarine migration of glass eels of the A merican eel (A nguilla rostrata). J ournal du Conseil International pour l'Exploration de la M er 40, 262-271. 
M cCleave, J. D. \& Wippelhauser, G. S. (1987). Behavioural aspects of selective tidal stream transport in juvenile A merican eels. A merican Fisheries Society Symposium 4, 138-150.

M oran, P. A. P. (1950). N otes on continuous stochastic phenomena. Biometrika 37, $17-23$.

M oriarty, C. (1990). European catches of elver of 1928-1988. Internationale R evue der Gesamten $\mathrm{H}$ ydrobiologie $\mathbf{7 5}, 701-706$.

M oriarty, C. (1993). The decline in catches of European elver 1980-1992. EIFAC Occasional Paper 27, 1-2,

Pritchard, D. W. (1952). Estuarine hydrography. In Advances in Geophysics, Vol. I, pp. 243-280. N ew Y ork: A cademic Press.

Sorensen, P. W. \& Bianchini, M. L. (1986). Environmental correlates of the freshwater migration of elvers of the A merican eel in a R hode Island brook. Transactions of the American Fisheries Society 115, 258-268.

Tesch, F. W. (1971). A ufenthalt der G lasaale (A nguilla anguilla) bei ihrer Wanderung in den Ä stuarien deutscher $\mathrm{N}$ ordseeflüsse. V ie et M ilieu 22, (supplement), 409-419.

Weber, M. (1986). Fishing method and seasonal occurrence of glass eels (Anguilla anguilla $\mathrm{L}$.) in the R io M inho, W est coast of the Iberian peninsula. Vie et M ilieu 36 (4), 243-250.

Wippelhauser, G. S. \& M cCleave, J. D. (1987). Precision of behaviour of migrating juvenile A merican eels (A nguilla rostrata) utilizing selective tidal stream transport. J ournal du Conseil International pour l'Exploration de la M er 44, 80-89. 